\title{
ANALISIS PERBANDINGAN AUDIT SYARIAH PADA LEMBAGA KEUANGAN ISLAM DI ASIA TENGGARA (STUDI LITERATUR DI INDONESIA, MALAYSIA, DAN BRUNEI)
}

\author{
Mutiara Kemala Ratu ${ }^{1}$ \\ Vhika Meiriasari ${ }^{2}$ \\ ${ }^{1}$ Fakultas Ekonomi, Universitas Indo Global Mandiri \\ Email : mutiarakemala.ratu@uigm.ac.id \\ ${ }^{2}$ Fakultas Ekonomi, Universitas Indo Global Mandiri \\ Email : vhikams@uigm.ac.id
}

\begin{abstract}
Penerapan audit syariah menjadi hal yang sudah semakin diperhatikan di berbagai negara, khususnya pada Indonesia, Malaysia, dan Brunei Darussalam Darussalam, yang merupakan negara anggota Organisation of Islamic Cooperation (OIC) di Asia Tenggara. Penelitian ini mengumpulkan berbagai literatur untuk melihat bagaimana pengaturan mengenai audit syariah yang merangkul secara menyeluruh pada lembaga keuangan syariah serta penerapan audit syariah yang sebenarnya dilakukan ketiga negara. Hasil temuan menunjukkan bahwa Shariah Governance Framework yang mengatur mengenai penggunaan framework audit syariah masih belum benar-benar diterapkan pada ketiga negara. Negara masih belum mengatur mengenai pengharusan peneraapan framework audit syariah sehingga penerapannya masih dilakukan secara sukarela oleh masing-masing lembaga keuangan. Oleh karena itulah, framework mengenai audit syariah masih beragam berdasarkan kebijakan yang dibuat oleh lembaga keuangan itu sendiri. Bahkan beberapa penelitian menunjukkan bahwa pengertian mengenai audit syariah masih belum ditangkap dengan baik oleh respondennya, terutama di negara Brunei Darussalam (perspektif mahasiswa sarjana dan paskasarjana). Maka dari itulah, temuan ini diharapkan mampu mendorong masing-masing regulasi syariah di ketiga negara untuk memantapkan framework audit syariah yang berlaku agar memiliki dasar framework yang sama di tiap lembaga keuangan syariah masing-masing negara. Penelitian ini merupakan penelitian kualitatif dengan metode literature review atas studi literatur audit syariah tahun 2012-2020 pada keseluruhan lembaga keuangan islam di Indonesia, Malaysia, dan Brunei Darussalam.
\end{abstract}

Keywords: Audit syariah, Shariah Governance Framework, IFI

\section{PENDAHULUAN}

Semakin berkembangnya ilmu dan teknologi yang ada dalam sistem keuangan di dunia tidak hanya mempengaruhi pada bidang keuangan konvensional saja, namun pada bidang keuangan islam atau syariah yang ikut merasakan dampaknya. Misalnya saja pada audit, aspek yang terdapat di dalam bahasannya sudah meluas termasuk cakupan pada bidang syariah. Audit syariah juga muncul atas dorongan karena dibutuhkannya kepastian dalam pemenuhan prinsip syariah yang dapat menumbuhkan kepercayaan stakeholders (Mardiyah \& Mardian, 2016).

Penerapan audit syariah juga menarik perhatian akademisi dalam penelitian mengenai perkembangan dan praktek audit syariah di berbagai negara (misalnya, Mardiyah and Mardian, 2016; Nawal Kasim, 2013; Ghani, N.L.A and Rahman, A.R.B., 2015; Yaacob, H., Shafeek, F. and Nahar, H.S., 2013). Meskipun sama-sama audit, tentu saja sistem yang ada didalam audit itu sendiri, baik syariah maupun konvensional akan memiliki perbedaan. Dalam memastikan keefektifan sistem pengendalian internal berdasarkan prinsip syariah, seorang auditor yang melaksanakan audit syariah harus mempunyai pengetahuan dan keterampilan memadai tentang fungsi audit syariah (Yaacob et al., 2013). Pelatihan dan pendidikan mengenai audit syariah menjadi kebutuhan untuk memenuhi keefektifan tersebut. Di Indonesia sendiri praktik pelatihan dalam rangka mendalami pemahaman dan kemampuan akan audit syariah sudah dilakukan oleh Muamalat Institute.

Adanya pelatihan mengenai audit syariah mengindikasikan bahwa masyarakat sudah tertarik akan perkembangan audit syariah itu sendiri. Perkembangan audit syariah tentu tidak hanya berada di Indonesia saja, namun juga pada Negara lain di Asia Tenggara seperti Malaysia dan Brunei Darussalam. Ketiga negara menarik untuk dijadikan objek penelitian karena ketiganya merupakan negara anggota 
Organisation of Islamic Cooperation (OIC) yang berada di Asia Tenggara, di mana hal tersebut berarti bahwa ketiganya memiliki keterkaitan dalam melakukan aktivitas Islamic. Berdasarkan data yang didapatkan pada webite resmi OIC, sampai Desember 2020 (Organization of Islamic Cooperation, 2020) terdapat 57 negara sebagai anggota didalamnya. Organisation of Islamic Cooperation (OIC) merupakan organisasi yang menyuarakan berbagai informasi dan kegiatan dalam dunia Muslim. OIC sebagai organisasi yang berperan untuk menjaga dan melindungi kepentingan dunia Muslim dalam semangat mempromosikan perdamaian dan harmoni internasional di berbagai orang di dunia. Penelitian ini sendiri hanya akan mengambil anggota OIC di Asia Tenggara, yaitu Negara Indonesia, Malaysia, dan Brunei Darussalam sebagai subejk penelitian dikarenakan hanya ketiga negara itulah yang termasuk sebagai member OIC. Untuk negara lain di Asia Tenggara seperti Negara India dan Filipina, tidak dimasukkan sebagai subjek penelitian karena belum menjadi anggota resmi OIC (pernah melakukan percobaan untuk menjadi anggota tetapi masih belum berhasil). Sedangkan negara Thailand sebagai negara yang memiliki populasi muslim yang signifikan juga tidak dimasukkan karena hanya merupakan negara pengamat (observers). Kemudian penelitian ini berfokus kepada berbagai literatur mengenai audit syariah berdasarkan teori atau aturan yang sudah ada beserta literatur dari penelitian sebelumnya mengenai audit syariah pada ketiga negara tersebut.

Penelitian ini bertujuan untuk melihat bagaimana penerapan dan perkembangan mengenai audit syariah beserta perbandingannya di negara Indonesia, Malaysia, dan Brunei Darussalam berdasarkan literatur yang telah dikumpulkan dari berbagai sumber. Seperti yang sebelumnya dijelaskan bahwa pengambilan ketiga negara tersebut dilakukan karena ketiganya merupakan anggota OIC, sehingga menandakan bahwa ketiga negara aktif menyuarakan kepentingan Muslim di dunia. Akan dilihat bagaimana penerapan audit syariah di ketiga negara. Audit syariah dinilai penting dalam menerapkan kepatuhan dan pengendalian internal secara syariah di seluruh sektor lembaga keuangan islam. Selanjutnya penelitian ini diharapkan mampu memberikan insights mengenai penerapan audit syariah, terutama di Indonesia, yangmana saat ini masih belum menerapkan audit syariah pada lembaga keuangannya.

\section{KAJIAN PUSTAKA Audit Syariah}

Audit syariah merupakan suatu proses pengauditan yang dilakukan atas dasar ketentuan syariah dalam memastikan seluruh kegiatan yang dilakukan oleh Islamic Financial Institution (IFI) yang diaudit masih sesuai dengan aturan yang berlaku (Minarni, 2013). Secara internasional aturan yang berlaku mengenai audit syariah tersebut dijelaskan dalam standar Accounting and Auditing Organization of Islamic Financial Institutions (AAOIFI). Adanya kemampuan evaluasi dari auditor terhadap segala informasi baik secara objektif (contohnya informasi atas pembagian keuntungan) maupun subjektif (informasi mengenai syariah) dalam memastikan kepatuhan sangatlah diperlukan (Wardayati and Wahid, 2016). Audit syariah juga ditujukan sebagai alat pengendalian internal sesuai syariah oleh auditor internal yang mempunyai pengetahuan dan keterampilan yang sejalan (Yaacob, 2012). Selain itu peran penting dari audit syariah ini tentu saja adalah untuk mengurangi terjadinya ketidakpatuhan syariah pada lembaga keuangan syariah (Najeeb and Ibrahim, 2014). Beberapa tujuan dalam audit syariah yang dijabarkan pada Accounting, Auditing and Governance for Takaful Operations (John Wiley \& Sons, 2012) :

(i) Membuat tata kelola yang efektif bagi perusahaan;

(ii) Akan diberikan penilaian secara independen dan jaminan objektif sedemikian rupa sehingga dapat memberikan nilai tambah dan meningkatkan kepatuhan mengenai operasi bisnis perusahaan;

(iii) melakukan audit atas kepatuhan Syariah dalam memastikan kegiatan yang dilakukan terhadap komponen produk dan layanan yang dilakukan oleh perusahaan masih sesuai dengan prinsip dan nilai syariah, yang dilakukan melalui pengamatan dan pengkajian ulang secara ketat halal dan melarang hal yang haram seperti yang diperintahkan oleh Allah Yang Maha Kuasa;

(iv) memiliki pemahaman yang lebih baik mengenai framework bisnis perusahaan dan untuk memastikan kepatuhan terhadap persyaratan Syariah.

(v) memastikan sistem pengendalian internal yang baik dan efektif untuk kepatuhan Syariah. 
Dengan berdasarkan prinsip syariat Islam, Audit Syariah diharapkan akan mampu mencapat objektif tertinggi dari Islamic law, yaitu Maqasid al-Shari'ah (Kasim et al., 2013; Othman and Ameer, 2015). Othman dan Ameer (2015) lebih lanjut menyatakan bahwa terdapat tiga Maqasid (Hifz-al-mal, Hifz-al-din dan Hifz-al-nasl) yang mengartikan ketika tabungan disimpan dengan aman pada bank syariah, maka bank syariah yang berperan sebagai agen (wakeel) pun akan mendapat fee atas pelayanan pengamanan tabungan. Keamanan yang dilakukan dalam menyimpan tabungan berdasarkan perspektif audit syariah harus dilakukan secara waspada dan hati-hati (Hifz-al-aql) agar tidak disalahgunakan manajemen atau kesalahan dalam pengalokasian aset non-shari'ah-compliant. Hal tersebut merupakan upaya agar terhindar dari asimetri informasi yang menandakan pelanggaran atas Hifz-al-din. Transparansi harus dilakukan seperti yang ditekankan Hifz-al-aql dan Hifz-al-mal dalam audit syariah. Selain itu auditor juga diharapkan memperluas pemahaman atau pandangan mengenai syariah, dimana auditor juga harus memperluas keahlian mereka agar mencapat substansi syariah yang lebih besar.

\section{Audit Syariah dalam IFI}

Dalam dunia keuangan shariah terdapat pengaturan mengenai tata kelola yang dikeluarkan oleh Islamic Financial Services Board, yaitu Shariah Governance Framework yang mengacu pada aturan kelembagaan dan organisasi. Hal tersebut kemudian diatur dalam IFI yang memastikan adanya pengawasan independen yang efektif mengenai kepatuhan syariah atas struktur dan prosespenerbitan pernyataan/ resolusi syariah yang relevan; penyebaran informasi mengenai resolusi syariah tersebut keada personil operasi IFI; tinjauan atau audit kepatuhan syariah internal; kepada tinjauan kepatuhan syariah tahunan atau audit untuk verifikasi tinjauan syariah internal (Wardhani and Arshad, 2012).

Shariah Governance Framework dirancang untuk memenuhi beberapa tujuan dalam IFI (Haqqi, A.R.A., 2014), yaitu:

(i) Menetapkan harapan Bank mengenai struktur, proses dan pengaturan tata kelola syariah IFI dalam memastikan bahwa semua kegiatan operasinya dan kegiatan usahanya sesuai dengan syariah;

(ii) memberikan panduan komprehensif kepada Dewan, Komite Syariah dan pengelolaan IFI dalam menjalankan tugasnya mengenai syariah;

(iii) menguraikan fungsi yang berkaitan dengan tinjauan syariah, audit syariah, manajemen risiko syariah dan penelitian syariah.

Dari ketiga fungsi yang dikeluarkan oleh Shariah Governance Framework tersebut, yang berhubungan dengan audit syariah dapat terlihat pada poin ketiga, yang menandakan bahwa pemenuhan framework audit syariah memang diperlukan agar dapat menguraikan fungsi dari audit syariah itu sendiri.

Tabel 1. Perbandingan antara audit konvensional dan audit syariah

\begin{tabular}{lll}
\hline No. & \multicolumn{1}{c}{ Audit Konvensional } & \multicolumn{1}{c}{ Audit Syariah } \\
\hline 1 & $\begin{array}{l}\text { Bertujuan serupa dengan audit syariah dalam hal } \\
\text { memberikan informasi kepada pengguna laporan } \\
\text { keuangan. }\end{array}$ & $\begin{array}{l}\text { Aturan lebih kompleks sehingga dibutuhkan } \\
\text { pemeriksaan yang lebih kompleks. }\end{array}$ \\
\hline 2. & $\begin{array}{l}\text { Sesuai dengan Anglo-American laws dan tidak } \\
\text { terikat dengan hukum atau kode agama apapun. } \\
\text { Auditor tidak bertanggung jawab atas pemeriksaan } \\
\text { praktik manajemen dan dampaknya terhadap } \\
\text { masyarakat. }\end{array}$ & \\
\hline 3. & Standar audit yang mengatur nya adalah IAI & Standar audit yang mengatur nya adalah AAOIFI \\
\hline $4 . \quad \begin{array}{l}\text { Berisikan opini mengenai wajar tidaknya } \\
\text { penyajian laporan keuangan perusahaan }\end{array}$ & $\begin{array}{l}\text { Berisikan opini mengenai sudah belumnya } \\
\text { terpenuhi Shari'a Compliance }\end{array}$ \\
\hline Sumber: Othman and Ameer (2014); Minarni (2013) &
\end{tabular}

Setiap aktivitas audit syariah terhadap lembaga keuangan syariah diawasi oleh Shariah Supervisor Board (SSB) atau kalau di Indonesia disebut sebagai Dewan Pengawas Syariah (DPS). DPS sendiri saat ini berperan pada fokus kepatuhan aturan dan prosedur serta kelengkapan dokumen dari IFI. Secara garis besarnya, ketika IFI bertujuan untuk mengoperasikan perusahaan mereka berdasarkan prinsip Islam (syariah), maka auditor syariah berperan dalam mempertanggung jawabkan kepastian atas kepatuhan syariah perusahaan yang di auditnya tersebut berdasarkan penugasan audit (Kasim et al., 2013). Dalam mencapai peningkatan kepatuhan dan nilai tambah operasi bisnis di IFI melalui penilaian yang independen dan jaminan obyektif, dilakukan audit syariah yang mengacu kepada penilaian secara 
berkala dari waktu ke waktu, sehingga akan tercapai kepastian sistem pengendalian internal yang efektif untuk kepatuhan syariah (Wardhani and Arshad, 2012). Secara fundamental dan konseptual perbandingan audit syariah dengan audit konvensional dapat dilihat pada tabel 1 .

\section{METODE PENELITIAN}

Penelitian ini merupakan penelitian kualitatif jenis literature review, dimana analisis pokok permasalahan akan dibahas dan diselesaikan melalui berbagai informasi dari teori atau aturan yang sudah ada beserta literatur dari penelitian sebelumnya. Analiasis akan dilakukan atas berbagai literatur dan penelitian terkait manapun dari tahun 2012-2020. Pengambilan literatur dimulai pada tahun 2012 dikarenakan penelitian yang mulanya dibuat dan diselesaikan pada tahun 2017 hanya akan mengambil data terbaru dalam kurun lima tahun terakhir terhitung dari tahun mulainya penelitian. Objek yang dibahas dalam penelitian ini adalah audit syariah pada lembaga keuangan islam di seluruh sektor keuangan di Indonesia, Malaysia, dan Brunei Darussalam. Ketiga negara yang dijadikan subjek penelitian diambil berdasarkan keanggotaannya dalam Organizational of Islamic Cooperation (OIC) yang berada di Asia Tenggara. Negara Thailand yang masih berada dalam OIC tidak dimasukkan sebagai subjek karena bukan termasuk negara anggota OIC namun hanya merupakan negara pengamat (observers) di OIC. Sedangkan negara lain di Asia Tenggara yang pernah melakukan percobaan untuk menjadi anggota, seperti Negara India dan Filipina tidak dimasukkan dalam penelitian karena saat ini mereka masih belum berhasil menjadi negara anggota OIC secara resmi.

\section{HASIL DAN PEMBAHASAN \\ Audit Syariah di Asia Tenggara}

Berdasarkan penjelasan pada bagian 1, telah di jelaskan mengapa dipilih negara Brunei Darussalam, Malaysia, dan Indonesia sebagai subjek penelitian dengan objek Audit Syariah di ketiga negara tersebut, dimana hal tersebut dikarenakan ketiga negara merupakan negara di Asia Tenggara dan juga merupakan negara anggota Organisation of Islamic Cooperation (OCI). Penelitian ini menggunakan metodologi kualitatif dengan membandingkan penerapan audit syariah di negara Brunei Darussalam, Malaysia, dan Indonesia.

\section{Brunei}

Menurut Wardhani and Arshad (2012) layanan perbankan syariah di Brunei Darussalam Darussalam menggunakan struktur pemerintahan full- fledged Islamic Banks, dengan tambahan dua bank syariah lain sebagai referensi dan perwakilan dari praktik industri, yaitu Perbadanan Tabung Amanah Islam Brunei (TAIB) and Bank Islam Brunei Darussalam (BIBD). Penambahan yang dilakukan adalah dalam rangka meningkatkan pemahaman mengenai peran Dewan Syariah di Brunei Darussalam .

Penelitian mengenai audit syariah di Brunei Darussalam dilakukan dengan melihat pemahaman atas audit syariah dari perspektif mahasiswa Undergraduate (Yaacob, H., Shafeek, F. and Nahar, H.S., 2013) dan Postgraduate (Yaacob and Donglah, 2012). Pada penelitan berdasarkan perspektif mahasiswa Postgraduate, ditemukan hasil yang menandakan bahwa masih banyaknya mahasiswa yang tidak memahami istilah audit syariah, bahkan perbedaannya dengan audit konvensional. Oleh karena itulah disini diharapkan para lulusan audit syariah mampu untuk turut terlibat dalam memperkenalkan audit syariah. Bahkan untuk auditor syariah itu sendiri masih diperlukan peningkatan pengetahuan dan kualitas misalnya dengan pelatihan dan sertifikasi khusus dalam syariah.

Pada perspektif undergraduate tidak jauh berbeda pada penelitian sebelumnya, ditemukan bahwa masih kurangnya pendalaman mengenai audit syariah kepada para mahasiswa secara komprehensif. Walaupun mereka setidaknya memiliki pemahaman dasar mengenai karakteristik peran dan etika auditor syariah, hal tersebut masih kurang. Masih sangat diperlukan adanya usaha yang lebih intensif dan terkoordinasi antara pemerintah, industri dan akademisi Hal tersebut diharapkan dikemudian hari akan mampu mengeluarkan auditor syariah yang berpengetahuan luas dan berkualitas sehingga dapat mengurangi atau menghilangkan bahaya pada industri audit syariah. Dari penelitian sebelumnya juga diharapkan peran media akan cukup membantu dalam menyebarkan informasi mengenai audit syariah kepada publik. 


\section{Malaysia}

Di Malaysia struktur pemerintahan yang digunakan adalah jenis stand-alone Islamic banks; Islamic banking windows within conventional banks; serta Islamic banking subsidiaries of conventional banks (Wardhani and Arshad, 2012). Untuk penelitian di Malaysia, dilakukan pula penelitian mengenai pemahaman dan pelaksanaan audit syariah di Malaysia atas persepsi mahasiswa akhir undergraduate (Shafii, et al, 2014). Hasilnya menunjukkan bahwa mayoritas dari mereka juga tidak begitu memahami akan audit syariah serta perbedaannya terhdap audit konvensional. Responden juga sepakat untuk pembuatan kerangka audit syariah haruslah mereka yang profesional di bidang tersebut.

Selanjutnya penelitian dilakukan oleh Ghani dan Rahman (2015) terhadap praktisi audit syariah Islamic Bank (IB) Malaysia. Hasilnya menunjukkan bahwa praktik audit syariah di IB Malaysia sangat diterima hanya dua tahun setelah dibutuhkannya Shariah Governance Framework (SGF). Penerimaan atas fungsi audit syariah berdasarkan SGF menandakan bahwa mayoritas IB di Malaysia telah berhasil dalam menetapkan tujuan audit; Pendirian divisi audit internal independen dan memiliki komunikasi dan konsultasi yang tepat dengan Komite Audit Dewan dan anggota Komite Syariah; kompentensi yang diperlukan auditor internal syariah, proses audit dan pelaporan yang dibutuhkan dalam melaksanakan audit syariah. Namun selain itu, terdapat pula pandangan responden yang tidak konsisten atas praktik audit syariah dalam audit scope and the audit charter.

Sementara hampir semua IB yang bermutu tinggi telah membentuk sebagian besar elemen dalam lingkup audit, tiga dari enam anak perusahaan Islam tidak mempertimbangkan audit atas laporan keuangan, kebutuhan anggota Komite Syariah untuk meninjau kembali kebijakan sumber daya manusia dan audit Syariah Pada sistem aplikasi teknologi informasi (Ghani, N.L.A and Rahman, A.R.B., 2015). Meskipun tidak konsisten dalam beberapa elemen praktik audit Syariah, hasilnya menunjukkan bahwa praktik audit Syariah telah dilakukan secara memadai oleh IB. Praktik audit syariah pada IB dilakukan dengan modernisasi dari kerangka audit internal konvensional (memiliki pedoman audit syariah sendiri).

\section{Indonesia}

Layanan perbankan syariah di Indonesia diperlihatkan melalui tiga jenis struktur pemerintahan, yaitu full-fledged Islamic Banks; Islamic windows under conventional banks; serta Islamic rural banks (Wardhani and Arshad, 2012). Praktik audit syariah di Indonesia saat ini memiliki fokus di empat masalah utamanya yaitu kerangka, ruang lingkup, kualifikasi dan independensi auditor syariah (Mardiyah \& Mardian 2016). Mengenai syariah, tanggung jawab dipegang oleh Dewan Pengawas Syariah (DPS) dengan framework pelaksanaan tugas asudit syariah yang masih belum dimiliki, sama seperti negara Brunei Darussalam dan Indonesia. Dalam papernya Mardiyah \& Mardian (2016) menjelaskan bahwa wewenang DPS terlebih dahulu diatur dalam UU No. 21/2008 dan Peraturan Bank Indonesia terkait, dengan prosedur aturan yang belum jelas. UU No. 21/2008 mengenai DPS hanya menjelaskan mengenai kewajiban pembentukan dan pengangkatan Dewan Pengawas Syariah oleh Rapat Umum Pemegang Saham dengan rekomendasi Majelis Ulama Indonesia. Sedangkan untuk prosedur aturan atas tugas yang diemban DPS tidak diatur, hanya menyatakan bahwa DPS bertugas memberikan nasihat serta saran untuk direksi dan turut mengawasi kegiatan Bank menyesuaikan Prinsip Syariah (Undang-Undang RI, 2008). Tidak dijelaskan bagaimana prosedur aturan atas Prinsip Syariah mana yang harus disesuaikan oleh DPS. Auditor syariah sendiri memiliki dua tujuan informasi dalam melakukan audit, yaitu objektif (seperti informasi mengenai keuangan pembagian keuntungan) dan subjektif (informasi mengenai syariah) yang ditujukan dalam memastikan kepatuhan syariah (Wardayati and Wahid, 2016).

\section{Tantangan Bagi Praktik Audit Syariah}

IFI mendapati tantangan yang cukup besar terhadap sistem konvensional yang memang sudah lebih matang, misalnya saja bagi auditor syariah dengan tantangan yang muncul dari pembuat kebijakan dan manajemen puncak yang berperan sebagai pemikir progresif atas berbagai praktik dan agama. Hal tersebut memang mungkin terjadi ketika IFI melakukan perluasan cakupan audit syariah kepada pengertian yang lebih sejalan dengan tujuan hukum Islam (Nawal Kasim, 2013).

Akan tetapi cakupan audit yang lebih islamic tersebut cukup sulit disamakan dan diterapkan secara penuh pada setiap negara yang memiliki lembaga keuangan syariah didalamnya karena adanya perbedaan sistem akuntansi setiap negara yang bersangkutan. Selain itu komparabilitas informasi keuangan dan hasil audit juga dapat terbatas karena penerapan standar akuntansi konvensional 
(Fakhfakh, 2017). Bahkan pada profesi auditing syariah, masih tidak jelas mekanisme pasar, struktur pasar, serta insentif didalamnya (Arman, S., 2013). Selain itu didapati pula bahwa masih kurangnya pengungkapan dalam Shariah Supervisory Board (SSB) yang dilakukan oleh bank syariah mengenai audit syariah (Abdullah, 2013). Nawal Kasim (2013) juga mengatakan bahwa adanya kerjasama antara orang-orang syariah dengan auditor internal merupakan hal terpenting untuk kesuksesan praktik audit syariah.

\section{PEMBAHASAN}

Praktik audit syariah dalam Lembaga Keuangan Islam, atau IFI, di Negara Indoensia, Malaysia dan Brunei Darussalam memang masih menghadapi kendala. Sebenarnya jika melihat perbandingan dengan audit konvensional dengan audit syariah, keduanya tidak sepenuhnya bertabrakan. Tujuan audit syariah internal sama dengan tujuan audit di lembaga keuangan konvensional, namun audit syariah pada perbankan islam memberikan jaminan bahwa transaksi harus sesuai dengan prinsip dan aturan syariah; standar Accounting and Auditing Organization of Islamic Financial Institutions (AAOIFI); dan standar akuntansi nasional (Algabry et al., 2020).

Besarnya tantangan dalam penerapan audit syariah yang dihadapi oleh auditor internal maupun eksternal terletak pada kurangnya pengetahuan dan keahlian mereka mengenai hal-hal yang terkait dengan syariah (Algabry et al., 2020; Abdul Rashid et al., 2017). Pengertian dan penerapan mengenai audit syariah yang lebih baik akan membuat investor dan pemberi pinjaman menjadi lebih aman (Fakhfakh, 2017). Di Malaysia sendiri, misalnya, mengenai audit syariah masih sedikit yang menjadi bahasan dalam kerangka kerja audit syariah Bank Sentral, sehingga kerangka kerja yang komprehensif atas audit syariah dalam IFI memang tepat untuk segera dilakukan (Nawal Kasim, 2013). Hingga saat ini, kerangka kerja mengenai audit syariah masih dikembangkan masing-masing oleh IFI, atau setidaknya mereka melakukan audit checklist (Nawal Kasim, 2013). Yaacob, H. (2012) menjelaskan bahwa fungsi audit syariah dijalankan oleh auditor syariah yang memiliki pengetahuan dan keterampilan mengenai syariah.

Sampai sekarang praktik audit syariah dalam IFI masih belum benar-benar diatur, baik di Indonesia, Malaysia, maupun di negara lain yang juga memiliki perbankan dan keuangan Islam (Nawal Kasim, 2013). Padahal seperti yang diketahui bahwa penerapan audit di konvensional dan syariah masih memiliki perbedaan, sehingga dapat memberikan informasi yang kurang jelas kepada pengguna laporan keuangan. Oleh karena itulah untuk mencapai keberhasilan dalam penerapan audit syariah, baik Negara Indonesia, Malaysia maupun Brunei Darussalam perlu meningkatkan pengetahuan dan keterampilan di bidang syariah sehingga menunjukkan pula bahwa framework audit syariah oleh masing-masing regulasi sangat dibutuhkan.

\section{KESIMPULAN}

Semakin berkembangnya akuntansi syariah di dunia mendorong kebutuhan yang semakin besar terhadap penggunaan berbagai fungsi syariah di lembaga keuangan yang menerapkan aturan secara islamic (lembaga keuangan syariah). Khususnya terhadap audit syariah yang sangat terlihat kebutuhannya untuk memeriksa kepatuhan syariah suatu lembaga keuangan syariah. Oleh karena itulah framework mengenai audit syariah yang profesional semakin dibutuhkan untuk sekarang (Najeeb, 2014). Namun walaupun sudah diharuskan menetapkan suatu framework atas audit syariah, ketetapan dari Shariah Governance Framework masih belum terpenuhi. Belum ada kriteria yang berlaku secara umum atas framework audit syariah, sehingga kalaupun lembaga keuangan syariah sudah memiliki framework audit syariah, hal tersebut masih berlaku bagi masing-masing lembaga keuangan syariah itu sendiri (masih beragam). Maka dari itulah didapatkan bahwa seharusnya regulator (syariah) di masing-masing negara dapat mengembangkan dan menerapkan framework audit syariah yang berlaku secara umum untuk lembaga keuangan syariah di negaranya.

Telepas dari wawasan dan pengetahuan mengenai penerapan audit syariah di Negara Indonesia, Malaysia, dan Brunei Darussalam yang diharapkan mampu disampaikan, penelitian ini mengakui masih adanya keterbatasan didalamnya. Pertama, subjek penelitian yang hanya mencakup tiga negara di Asia Tenggara, yaitu Indonesia, Malaysia, dan Brunei Darussalam. Studi selanjutnya mungkin bisa memperluas cakupan negara yang bersangkutan. Kedua, adanya keterbatasan dalam pengumpulan literatur dimana literatur yang digunakan lebih banyak menunjukkan pada Lembaga Keuangan Islam di sektor perbankan. Oleh karena itulah penelitian selanjutnya diharapkan dapat memperbanyak atau menyeimbangkan penggunaan literatur di seluruh sektor Lembaga Keuangan Islam. 


\section{REFERENSI}

Accounting, Auditing and Governance for Takaful Operations. (2012). Accounting, Auditing and Governance for Takaful Operations. John Wiley \& Sons, Inc. https://doi.org/10.1002/9781119198970

Abdul Rashid, A., Abdul Hamid, M., Mohamad Sidek, A. S., Wan Abdullah, W. M. T., \& Mohd Ali, I. (2017). Shari'ah Auditing: A Review of Shari'ah Audit Practices in Islamic Financial Institution (IFIs). SHS Web of Conferences, 36, 00019. https://doi.org/10.1051/shsconf/20173600019

Algabry, L., Alhabshi, S. M., Soualhi, Y., \& Alaeddin, O. (2020). Conceptual framework of internal Shar' 'ah audit effectiveness factors in Islamic banks. ISRA International Journal of Islamic Finance, 12(2), 171-193. https://doi.org/10.1108/IJIF-09-2018-0097

Amalina Wan Abdullah, W., Percy, M., \& Stewart, J. (2013). Shari'ah disclosures in Malaysian and Indonesian Islamic banks. Journal of Islamic Accounting and Business Research, 4(2), 100-131. https://doi.org/10.1108/jiabr-10-2012-0063

Arman, S. M. (2013). Shariah Compliance Features of Islamic Financial Institutions and Its Challenges. Oman Chapter of Arabian Journal of Business and Management Review, 3(4), 91-98. doi:10.12816/0016447

Fakhfakh, M. (2017). The harmonization of audit reports of Islamic banks: An advanced and original empirical investigation. Journal of Islamic Accounting and Business Research, 8(2), 203-228. https://doi.org/10.1108/JIABR-05-2014-0016

Ghani, N. L. A., \& Rahman, A. R. A. (2015). An analysis of Shari'ah audit practices in islamic banks in Malaysia. Jurnal Pengurusan, 43, 107-118.

Haqqi, A. R. A. (2014). Shari'ah governance in Islamic financial institution: An appraisal. US-China Law Review, 11, 112-113. Retrieved from www.isra.my

Kasim, N., Sanusi, Z. M., Mutamimah, T., \& Handoyo, S. (2013). Assessing the current practice of Auditing in Islamic Financial Institutions in Malaysia and Indonesia. International Journal of Trade, Economics and Finance, 414-418. https://doi.org/10.7763/ijtef.2013.v4.328

Mardiyah, Q., \& Mardiyah, S. (2016). PRAKTIK AUDIT SYARIAH DI LEMBAGA KEUANGAN SYARIAH INDONESIA. Akuntabilitas, 8(1). https://doi.org/10.15408/akt.v8i1.2758

Minarni, M. (2013). AUDIT SYARIAH, DAN TATA KELOLA LEMBAGA KEUANGAN SYARIAH. La_Riba, 7(1), 29-40. https://doi.org/10.20885/lariba.vol7.iss1.art3

Najeeb, S. F., \& Ibrahim, S. H. M. (2014). Professionalizing the role of Shari'ah auditors: How Malaysia can generate economic benefits. Pacific Basin Finance Journal, 28, 91-109. https://doi.org/10.1016/j.pacfin.2013.10.009

Nawal Kasim, N. K. (2013). Emerging issues for auditing in Islamic Financial Institutions: Empirical evidence from Malaysia. IOSR Journal of Business and Management, 8(5), 10-17. https://doi.org/10.9790/487x-0851017

Organization of Islamic Cooperation. (2020). Member States. Retrieved from https://www.oicoci.org/states/?lan=en

Othman, R., \& Ameer, R. (2015). Conceptualizing the duties and roles of auditors in islamic financial institutions what makes them different? Humanomics, 31(2), 201-213. https://doi.org/10.1108/H04-2013-0027

Shafii, Z., Salleh, S., Zakaria, N., Hanefah, M. M., Mohd Ali, N. A., \& Yunanda, R. A. (2014). Shariah Audit Certification Contents: Views of Regulators, Shariah Committee, Shariah Reviewers and Undergraduate Students. International Journal of Economics and Finance, 6(5). https://doi.org/10.5539/ijef.v6n5p210

Undang-Undang RI, P. S. (2008). UNDANG-UNDANG REPUBLIK INDONESIA NOMOR 21 TAHUN 2008 TENTANG PERBANKAN SYARIAH. Otoritas Jasa Keuangan (pp. 69-73). Retrieved from https://www.ojk.go.id/waspadainvestasi/id/regulasi/Documents/UU_No_21_Tahun_2008_Perbankan_Syariah.pdf

Wardayati, S. M., \& Al Wahid, A. M. (2016). PANDANGAN INSTITUSI KEUANGAN ISLAM TERHADAP AUDIT SYARIAH. Jurnal Fenomena, 8(2), 111-126.

Wardhany, N., \& Arshad, S. (2012). The Role of Shariah Board in Islamic Banks: A Case Study of Malaysia, Indonesia and Brunei Darussalam. 2nd ISRA Colloquium "Islamic Finance Is $n$ Challenging Economy: Moving Forward," (November), 1-26. 
Yaacob, H. (2012). Issues and Challenges of Shari?ah Audit in Islamic Financial Institutions: A Contemporary View. SSRN Electronic Journal. https://doi.org/10.2139/ssrn.2175700

Yaacob, H., \& Donglah, N. K. (2012). Shari'ah Audit in Islamic Financial Institutions: The Postgraduates' Perspective. International Journal of Economics and Finance, 4(12). https://doi.org/10.5539/ijef.v4n12p224

Yaacob, H., Shafeek, F., \& Nahar, H. S. (2013). Exploring Undergraduate Students' Understanding of Shari'ah Based Audit: Implications for the Future of Shari'ah Auditing Labor Market in Brunei. Asian Journal of Finance \& Accounting, 5(2), 84. https://doi.org/10.5296/ajfa.v5i2.4039 